\title{
A Nacionalização do Gás Boliviano e o Processo de InTEgRaÇão Econômica: uma Análise Retroativa
}

\author{
Paulo Roberto Silva ${ }^{(*)}$
}

\begin{abstract}
Resumo: Durante os anos de 1990, Brasil e Bolívia construíram um importante acordo de integração econômica por meio do comércio de gás natural. Construíram em conjunto um gasoduto, estabeleceram um contrato de fornecimento e criaram um comércio até então inexistente. Em 2006, contudo, a insatisfação boliviana com os termos do comércio e seus baixos impactos sociais levaram a um tenso processo de revisão dos acordos existentes. Quatro anos depois, é possível avaliar, com base nos indicadores econômicos disponíveis, se o intercâmbio bilateral e a integração econômica avançaram ou regrediram após 2006, em comparação com os níveis registrados nos anos anteriores.
\end{abstract}

Palavras-chave: Brasil, Bolívia, Integração Econômica, Comércio Internacional, Gás Natural.

Abstract: In 1990s years, Brazil and Bolivia have built a important agreement for economic integration through trade of natural gas. They build along a pipeline, firmed a supply contract and created a trade where none exists. In 2006, however, the Bolivian dissatisfaction with terms of trade and their low social impacts have led to a tense process of revision of current agreements. Four years later, can be evaluate based in economic indicators available, if a bilateral trade and economic integration progressed or regressed after 2006, compared with levels levels in previous years.

Keywords: Brazil, Bolivia, Economic Integration, International Trade, Natural Gas.

(*) Mestrando do Programa de Pós-Graduação em Integração da América Latina da Universidade de São Paulo. E-mail: <pbelushi@gmail.com>. Recebido em 20.6.2010 e aceito em 23.9.2010. 


\section{A naCionalização do gás boliViano E O PROCESSO de INTEGRAÇÃo ECONÔMICA: UMA ANÁLISE RETROATIVA}

Os movimentos políticos da Bolívia em relação a suas exportações de gás natural ao Brasil realizados durante o ano de 2006 alteraram o rumo da integração econômica entre os dois países. Um olhar distanciado no tempo — quatro anos — nos permite avaliar de forma mais precisa quais as variáveis que interferiram de forma efetiva na evolução da economia e do processo de integração neste período.

Para compreender as mudanças ocorridas no processo de integração, é importante começar traçando um histórico do comércio recente de gás natural entre Brasil e Bolívia e seu desenvolvimento até a eleição de Evo Morales em 2005. Em seguida, trataremos dos fatos ocorridos no país a partir de $1^{\underline{0}}$ de maio de 2006, e a negociação subsequente entre Brasil e Bolívia no decorrer daquele ano. O próximo passo será analisar a evolução do comércio internacional e do marco institucional entre 2006 a 2009, procurando identificar avanços e retrocessos no processo de integração econômica.

\section{Histórico do COMÉRCIO DE GÁs NATURAL}

O primeiro acordo bilateral entre Brasil e Bolívia relativo aos hidrocarbonetos data de 1938, quando os governos dos dois países firmaram um acordo sobre a saída e o aproveitamento do petróleo boliviano (MRE, 1938). O acordo de então previa investimentos da ordem de US\$1,5 milhão em pesquisas geológicas para identificação de reservas de petróleo na região subandina boliviana, e estabelecia que a exploração de petróleo seria realizada por meio de sociedades mistas brasileiro-bolivianas, além de assegurar a construção de oleodutos entre as áreas de produção e a fronteira brasileira.

A existência deste acordo surpreende pelo fato de que o Brasil não contava com empresas nacionais de exploração e produção de petróleo. A Petrobras só viria a ser constituída em 1953. Já a Yacimientos Petroliferos Fiscales Bolivianos (YPBF) foi constituída em 1936, dois anos antes, e assumiu os ativos da Stardard Oil no país, expulsa sob acusações de corrupção (YPFB, 2006). Além disso, os hidrocarbonetos bolivianos não fariam parte do planejamento energético brasileiro realizado durante a crise do petróleo nos anos 1970, como afirmam Barufi, Santos e Ide (2006: 186).

De qualquer forma, as conversações continuaram. Em fevereiro de 1978, os chanceleres Azeredo da Silveira do Brasil e Garcia Rivera da Bolívia firmaram um acordo que permitia a instalação de um escritório da YPFB no Rio de Janeiro (MRE, 1978). O acordo estabelecia isenções do imposto de importação para aquisição dos bens necessários à instalação do escritório e dos funcionários da estatal boliviana, além de prever benefícios semelhantes para uma pessoa jurídica brasileira similar à YPFB na Bolívia.

Se havia a possibilidade de as conversações sobre intercâmbio de petróleo e gás natural avançarem entre Brasil e Bolívia, a crise da dívida parecia ter interrompido este andamento. Contudo, o tema voltou às conversações oficiais entre os dois países na 
década de 1990. Em agosto de 1992, o chanceler brasileiro Celso Lafer firmou um acordo com seu par boliviano Ronald Mac Lean para viabilizar o comércio bilateral de gás natural (MRE, 1992). Os dois governos firmaram, ao mesmo tempo, tanto um acordo de alcance parcial de comércio, no âmbito da Associação Latino-americana de Integração (Aladi), quanto um contrato de compra e venda de gás natural entre a Petrobras e a YPFB. O acordo previa a aquisição inicial de 8 milhões de metros cúbicos diários, atingindo 16 milhões entre 7 e 10 anos e podendo alcançar 30 milhões no máximo (INTAL, 1996, p. 93). O preço do gás foi calculado levando em consideração o preço do óleo combustível no estado de São Paulo, combustível que foi substituído pelo gás boliviano.

Apesar de ser um período de forte crise institucional no Brasil, com o processo de impeachment do presidente Fernando Collor em andamento, o processo continuou. Em fevereiro de 1993, já sob o governo de Itamar Franco, o chanceler brasileiro Fernando Henrique Cardoso firmou com seu par boliviano um novo acordo (MRE, 1993), detalhando o contrato de compra e venda entre Petrobras e YPFB. Em 1996, o presidente da Agência Nacional do Petróleo (ANP), firmou com a chancelaria boliviana um novo acordo, para assegurar tanto a isenção de imposto de importação dos equipamentos para a construção do gasoduto Brasil-Bolívia quanto detalhar o processo de concessão do gasoduto nos dois países (MRE, 1996). No mesmo ano, Petrobras e YPFB firmaram um adendo ao contrato original, que garantiu à Petrobras 15\% de participação na concessionária do gasoduto do lado boliviano e à YPFB 20\% na equivalente brasileira (INTAL, 1996, p. 93).

A partir desse momento, a evolução este tema tomou dois rumos distintos. No âmbito industrial, seguiu-se a construção do gasoduto Brasil-Bolívia, concluído em 1999, e a assinatura enfim do Gas Supply Agreement(GSA) entre Petrobras e YPFB (BNAméricas, 2000). No âmbito político, os debates evoluíram para uma integração energética mais ampla. Em março de 1998, os chanceleres Luiz Felipe Lampreia do Brasil e Javier Murillo de la Rocha da Bolívia firmaram um memorando de entendimentos genérico sobre integração energética. Em maio de 2002, os dois países firmaram um acordo para criar uma comissão mista bilateral permanente em matéria energética, com o objetivo de aprofundar a discussão sobre a integração energética. Aparentemente os dois países pretendiam criar um ciclo virtuoso de integração, a partir da evolução do comércio de gás natural.

Uma amostra deste esforço está na aproximação entre Bolívia e Mercosul. Em 1996, o Mercosul firmou um acordo de cooperação econômica com a Bolívia. A partir de 2003, a Bolívia passou a fazer parte das reuniões do Mercosul, como membro associado.

Este processo de integração pode ser compreendido tanto pelas transformações que aconteciam no ambiente econômico boliviano quanto pelo momento político latino-americano. De acordo com um estudo realizado por Wiegers para o INTAL, a Bolívia implantou durante os anos de 1990 uma política de desregulamentação e abertura para facilitar o acesso do capital privado ao setor, mediante venda, concessão ou capitalização de empresas (1996, p. 15). Esta era uma tendência regional, uma vez que em questão de três ou quatro anos o perfil dos pedidos de financiamento no Banco Interamericano de Desenvolvimento alterou-se feitos exclusivamente estatais para uma presença crescente do setor privado nos projetos (1996, p. 100). 
A desregulamentação boliviana consistia em manter o monopólio da exploração e comercialização dos hidrocarbonetos (petróleo e gás) sob controle da YPFB. Contudo, a operação poderia ser transferida a terceiros por meio de licitação pública, mediante a qual a YPFB transferia os seus direitos a um agente privado mediante um contrato de concessão. Em 1996, a desregulamentação deu mais um passo, com a YPFB sendo cindida em cinco companhias diferentes, submetidas à privatização (1996, p. 106). Os impactos sociais desta medida serão avaliados adiante.

Se a desregulamentação do setor criou um ambiente favorável aos investimentos em exploração de petróleo e gás na Bolívia, a onda de ações de integração regional na América Latina dos anos de 1990 criou estímulos à interconexão (FFRENCH-DAVIS; DEVLIN, 1998, I). De acordo com Ffrench-Davis e Devlin, as exportações da região cresceram 97\% entre 1990 e 1997. A participação do comércio intrarregional nas exportações saltou de $12 \%$ para $18 \%$ do total (Id: 3). Esse avanço do comércio teria sido resul-tado de uma maior abertura ao setor exertno da qual a integração regional sob a marca do regionalismo aberto teria sido um dos pilares, acompanhado da abertura unilateral e multilateral ao comércio (Id: 11).

Considerando que do ponto de vista institucional o comércio de gás avançava para a integração energética e uma aproximação entre Bolívia e Mercosul, podemos considerar que estava em curso um círculo virtuoso de integração entre aquele país e o Brasil. De fato, análise da Cepal aponta que "a derrubada de barreiras ao livre intercâmbio leva a um aumento do volume de comércio em relação ao nível de produção interna dos países participantes, o que significa que se deve esperar um aumento do grau de abertura destes países" (CEPAL, 1992, p. 198).

\section{O DeSEnVolvimento do COMÉRCio de GÁS NATURAL de 2000 A 2006}

Em 2000, o Gasoduto Brasil Bolívia começou a operar, apresentando resultados acima dos esperados. De acordo com a ANP, a importação de gás saltou de 6 milhões de metros cúbicos médios por dia em 2000 para 22 milhões em 2004, mais do que Petrobras e YPFB esperavam em até 10 anos, conforme a Tabela 1.

\section{Tabela 1 - Importação de gás natural, em mil metros cúbicos médios por dia}

\begin{tabular}{|ll|}
\hline 2000 & 6.034 \\
\hline 2001 & 12.609 \\
\hline 2002 & 14.442 \\
\hline 2003 & 16.201 \\
\hline 2004 & 22.096 \\
\hline
\end{tabular}

Fonte: Agência Nacional do Petróleo (2008, p. 24-25). 
Do ponto de vista econômico, a integração energética criou uma corrente de comércio até então inexistente entre Brasil e Bolívia, com fortes vantagens para este último. Neste sentido, esta integração cumpria uma das exigências de Vinner, isto é, a criação de comércio entre os membros da área de integração, o que significa um movimento rumo ao livre comércio (BALASSA, 1961, p. 26-27). De acordo com dados do Aliceweb, base de dados de comércio exterior do Ministério do Desenvolvimento, as exportações bolivianas saltaram de US\$ 140 milhões para US\$ 713 milhões de 2000 a 2004, conforme mostra a Tabela 2. Este salto foi gerado exclusivamente pelo intercâmbio de gás natural, que saltou de US\$ 110 milhões para US\$ 562 milhões no mesmo período. Como as importações cresceram em menor proporção, de US $\$ 364,6$ milhões para US\$ 540 milhões, a Bolívia saiu de um déficit de US\$224,4 milhões para um superávit comercial de 172,9 milhões, enquanto os termos de troca evoluíram em favor da Bolívia, de 0,38 para 1,32 .

\section{Tabela 2 - Comércio Bilateral entre Brasil e Bolívia, em US\$ milhões}

\begin{tabular}{|c|c|c|c|c|c|}
\hline & Importações & Exportações & $\begin{array}{c}\text { Gás para } \\
\text { o Brasil }\end{array}$ & $\begin{array}{c}\text { Termo de } \\
\text { Troca }\end{array}$ & $\begin{array}{c}\text { Saldo } \\
\text { comercial }\end{array}$ \\
\hline 2000 & 364,6 & 140,2 & 110,4 & 0,38 & $-224,4$ \\
\hline 2001 & 334,4 & 256,1 & 174,6 & 0,77 & $-78,3$ \\
\hline 2002 & 422,2 & 395,8 & 331,8 & 0,94 & $-26,4$ \\
\hline 2003 & 362,4 & 520,4 & 410 & 1,44 & 158 \\
\hline 2004 & 540,4 & 713,3 & 562,2 & 1,32 & 172,9 \\
\hline
\end{tabular}

Fonte: Aliceweb.

Contudo, apesar do desenvolvimento positivo do comércio de gás natural, a sociedade boliviana começou a questionar politicamente a corrente de comércio. Em 2002, Evo Morales esteve próximo de ser eleito com uma plataforma voltada à nacionalização do gás (UCHÔA, 2002). Em 2003, o presidente eleito Sanchez de Losada foi derrubado por meio de uma forte mobilização popular. Seu sucessor, Carlos Mesa, assumiu com o compromisso de chamar um referendo sobre a exportação de gás natural (MAISONNAVE, 2003). O referendo, realizado em 18 de julho de 2004, aprovou por 92,1\% a nacionalização do gás natural “na boca do poço” (MAISONNAVE, 2004).

Contudo, divergências sobre detalhes da nova regulamentação dos hidrocarbonetos levaram a uma nova crise política em março de 2005, quando o presidente Carlos Mesa apresentou pedido de renúncia, rejeitado pelo Congresso (MAISONNAVE, 2005). A tensão política subiu e o presidente Mesa enfim foi deposto, cedendo o lugar ao presidente da Corte Suprema de Justiça, Eduardo Rodriguez (MAISONNAVE, 2005). Rodriguez assume com o compromisso de convocar novas eleições, que foram vencidas por Evo Morales com 44,5\% dos votos em 18 de dezembro de 2005 (MAISONNAVE, 2005). 
Morales passou de dezembro de 2005 a abril de 2006 transmitindo sinais de que queria reavaliar o comércio de gás natural com o Brasil. Até que, no primeiro de maio, o governo boliviano mandou o exército invadir as refinarias da Petrobras na Bolívia, criando o fato político da renegociação dos termos de comércio (MAISONNAVE, 2006). As exigências do governo boliviano diziam respeito ao marco regulatório dos hidrocarbonetos e ao comércio de gás natural. No campo regulatório, o governo exigiu ampliar a participação estatal na exploração e refino de petróleo e gás. No comércio, exigiu a elevação do imposto sobre o gás de $50 \%$ para $82 \%$.

Por que, apesar do evidente crescimento do comércio, a insatisfação de parcela importante da sociedade boliviana questionou suas condições e se mobilizou politicamente contra ele, chegando a forçar a mudança de governo? O desempenho econômico do período nos dá algumas informações relevantes.

De 2000 a 2004, apesar do crescimento do comércio, a economia boliviana sofreu uma forte estagnação. O PIB boliviano no período oscilou de US $\$ 8,4$ bilhões para US $\$$ 8,8 bilhões, de acordo com a Tabela 3. De certa forma, a expansão do comércio internacional ajudou a compensar uma queda de atividade econômica em outros setores da economia. As exportações saltaram de 14,8\% do PIB para 24,9\% no período, e as exportações de gás para o Brasil saltam de $1,3 \%$ para $6,4 \%$.

\section{Tabela 3 - Evolução do PIB Boliviano e da participação das exportações}

\begin{tabular}{|c|c|c|c|}
\hline & PIB (US\$ bilhões) & \% Exportações & $\begin{array}{c}\text { \% Exportações gás } \\
\text { Brasil }\end{array}$ \\
\hline 2000 & 8,4 & $14,80 \%$ & $1,30 \%$ \\
\hline 2001 & 8,1 & 15 & $2,10 \%$ \\
\hline 2002 & 7,9 & $16,70 \%$ & $4,20 \%$ \\
\hline 2003 & 8 & $19,60 \%$ & $5,10 \%$ \\
\hline 2004 & 8,8 & $24,90 \%$ & $6,40 \%$ \\
\hline
\end{tabular}

Fonte: FMI, Instituto Nacional de Estadísticas e Aliceweb.

Quando desdobramos o PIB boliviano por tipo de gasto a preços constantes, percebemos que o consumo das famílias e a formação bruta de capital fixo perderam espaço para as exportações no período de 2000 a 2004, conforme a Tabela 4. 
Tabela 4 - Participação do tipo de gasto no PIB boliviano

\begin{tabular}{|c|c|c|c|c|c|}
\hline & $\begin{array}{c}\text { Administração } \\
\text { Pública }\end{array}$ & $\begin{array}{c}\text { Consumo das } \\
\text { Famílias }\end{array}$ & $\begin{array}{c}\text { Formação Bruta } \\
\text { de Capital Fixo }\end{array}$ & Exportações & Importações \\
\hline 2000 & $14,54 \%$ & $76,37 \%$ & $17,89 \%$ & $18,27 \%$ & $27,32 \%$ \\
\hline 2001 & $15,72 \%$ & $75,29 \%$ & $13,93 \%$ & $19,97 \%$ & $25,26 \%$ \\
\hline 2002 & $15,97 \%$ & $73,82 \%$ & $15,65 \%$ & $21,63 \%$ & $27,72 \%$ \\
\hline 2003 & $16,52 \%$ & $71,01 \%$ & $12,66 \%$ & $25,60 \%$ & $26,37 \%$ \\
\hline 2004 & $16,26 \%$ & $67,91 \%$ & $11,69 \%$ & $31,14 \%$ & $26,33 \%$ \\
\hline
\end{tabular}

Fonte: Instituto Nacional de Estadísticas.

O cruzamento destas informações mostra que, enquanto o comércio internacional boliviano crescia, por conta da exportação de gás natural para o Brasil, a população boliviana estava empobrecendo. Além disso, a queda na taxa de investimento, apontada pela formação bruta de capital fixo, sinalizou uma tendência a manter este nível de empobrecimento nos anos seguintes, uma vez que "o emprego só pode aumentar pari passu com um aumento do investimento” (KEYNES, 1992, p. 89).

Além disso, é importante destacar que a indústria de hidrocarbonetos, principal beneficiária do crescimento do comércio internacional boliviano, não era intensiva em trabalho, o que reduziu o seu potencial de impactar positivamente a atividade econômica por meio dos salários. Esta baixa elasticidade de emprego da indústria de hidrocarbonetos pode ser identificada na baixa variação do índice de emprego do setor de 1996, quando se iniciou a construção do Gasoduto Brasil-Bolívia, a 2009, apontada no Gráfico 1.

\section{Gráfico 1 - Índice de emprego na indústria boliviana de extração de petróleo e gás}

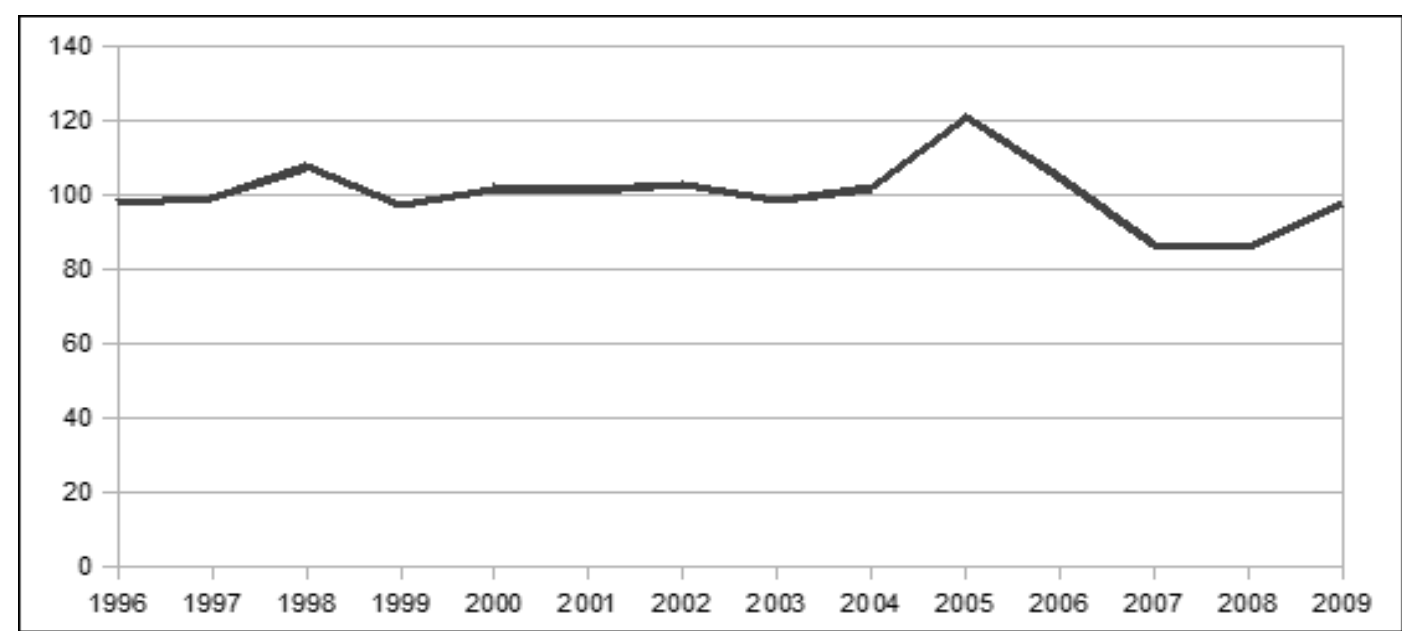

Fonte: Instituto Nacional de Estadísticas. 
Ou seja, além de as exportações de gás natural não serem revertidas em renda para as famílias ou expansão da taxa de investimento, a própria constituição desta indústria, por si mesma, não se reverteu em mais atividade econômica por meio da expansão do emprego. Afinal, "se, por exemplo, a demanda suplementar for em grande parte dirigida para as indústrias com alta elasticidade de emprego, o aumento agregado de emprego será maior do que se o mesmo se orientar para as indústrias que oferecem baixa elasticidade de emprego" (KEYNES, 1992, p. 224).

Para que uma indústria como esta traga melhora da qualidade de vida ao conjunto da sociedade, é necessário criar mecanismos que levem a uma mais distribuição da renda gerada. A opção feita pela Bolívia foi pela apropriação estatal da renda dos hidrocarbonetos, que seria redistribuída por meio de um plano de desenvolvimento econômico (GIL, 2008, p. 44). Não nos cabe neste trabalho analisar o modelo de desenvolvimento boliviano, mas avaliar se, a partir da reviravolta política que desencadeia um conflito dentro do processo de integração, esta permanece avançando ou sofre algum grau de retração.

\section{O COMÉRCIO E A INTEGRAÇÃo APÓS 2006}

A mudança no marco regulatório da indústria de hidrocarbonetos na Bolívia, que obrigou os investidores privados a formarem joint ventures com a estatal YPFB e elevou a tributação sobre a exportação de gás, além da revisão do Gas Supply Agreement que permitiu precificar o "valor agregado" do gás natural. O comércio do combustível passou por uma nova expansão, conforme os dados da Tabela 5. De US $\$$ 783,6 milhões em 2005, saltou para US $\$ 2,7$ bilhões em 2008 e reduziu-se para US $\$ 1,6$ bilhões em 2009 por conta da crise econômica. O saldo comercial com o Brasil registrou superávit crescente, de US\$ 404,5 milhões em 2005 para US $\$ 1,7$ bilhões em 2008, retraindo para US $\$ 730$ milhões em 2009.

Tabela 5 - Comércio bilateral entre Brasil e Bolívia, em US\$ milhões

\begin{tabular}{|c|c|c|c|c|c|}
\hline & Importações & Exportações & $\begin{array}{c}\text { Gás para o } \\
\text { Brasil }\end{array}$ & $\begin{array}{c}\text { Termo de } \\
\text { Troca }\end{array}$ & $\begin{array}{c}\text { Saldo } \\
\text { comercial }\end{array}$ \\
\hline 2005 & 585,20 & 989,80 & 783,60 & 1,69 & 404,50 \\
\hline 2006 & 701,60 & $1.448,20$ & $1.261,40$ & 2,06 & 746,60 \\
\hline 2007 & 850,70 & $1.601,12$ & $1.472,10$ & 1,88 & 750,40 \\
\hline 2008 & $1.135,60$ & $2.857,90$ & $2.677,20$ & 2,52 & $1.722,30$ \\
\hline 2009 & 919,20 & $1.649,70$ & $1.591,30$ & 1,79 & 730,50 \\
\hline
\end{tabular}

Fonte: Aliceweb.

Ou seja, apesar de a Bolívia ter imposto restrições ao comércio, ele cresceu no período posterior à crise de 2006, e não diminuiu. A exceção, evidentemente, é 2009, ano 
em que a crise econômica interferiu na atividade industrial e, por consequência, no consumo de energia. É importante enfatizar que o período posterior a 2006 coincidiu com taxas de crescimento elevadas do PIB brasileiro, o que teve como consequência uma maior demanda por energia. É difícil avaliar se a Bolívia obteve o mesmo resultado em um cenário de recessão econômica no Brasil.

O crescimento da corrente de comércio impactou positivamente o PIB boliviano, que saiu do cenário de estagnação. Contudo, a economia tornou-se a curto prazo mais dependente da exportação de um único produto para um único mercado: a exportação de gás para o Brasil chegou a representar 16\% do PIB, como aponta a Tabela 6 .

\section{Tabela 6 - Evolução do PIB boliviano e da participação das exportações}

\begin{tabular}{|c|c|c|c|}
\hline & PIB (US\$ bilhões) & \% Exportações & $\begin{array}{c}\text { \% Exportações gás } \\
\text { Brasil }\end{array}$ \\
\hline 2005 & 9,6 & $29,95 \%$ & $8,20 \%$ \\
\hline 2006 & 11,5 & $35,47 \%$ & $10,90 \%$ \\
\hline 2007 & 13,3 & $36,28 \%$ & $11,10 \%$ \\
\hline 2008 & 16,6 & $41,56 \%$ & $16,10 \%$ \\
\hline 2009 & 17,5 & $30,18 \%$ & $9,10 \%$ \\
\hline
\end{tabular}

Fonte: FMI, Instituto Nacional de Estadísticas e Aliceweb.

Do ponto de vista institucional, também houve continuidades. Após o duro período de negociações de 2006, o Mercosul instituiu em janeiro de 2007 um grupo de trabalho para discutir a adesão da Bolívia como membro pleno ao Mercosul. O presidente brasileiro Luís Inácio Lula da Silva fez uma visita de estado à Bolívia em dezembro de 2007 e firmou uma série de acordos de cooperação técnica, além de uma declaração conjunta afirmando que "todas as ações desenvolvidas terão como objetivo central avançar em direção a uma parceria estratégica” (MRE, 2007, p. 1). Nos anos seguintes, novos acordos de cooperação técnica foram firmados, no sentido de troca de experiências para implantação de políticas públicas na Bolívia.

Os principais atos internacionais econômicos deste período foram a Declaração de Riberalta, firmada em 18 de julho de 2008, por meio da qual o Brasil concedeu financiamento para construção de obras de infraestrutura na Bolívia, e o acordo de cooperação energética firmado entre o Ministério das Minas e Energia do Brasil e Ministério dos Hidrocarbonetos da Bolívia, no qual o Brasil se comprometeu a realizar novos investimentos na Bolívia.

Contudo, a partir de 2006, o Brasil passou a apostar em novas fontes de gás natural, tanto nacionais quanto internacionais, como mostra a Tabela 7. De 2007 a 2008, a produção nacional de gás descolou da importação, saltando de 26,9 mil para 34,5 mil 
metros cúbicos por dia. No mesmo período, a importação cresceu menos, oscilando de 28,3 mil para 30,9 mil metros cúbicos por dia. Tratou-se de um esforço brasileiro em reduzir sua exposição a crises como a de 2006, elevando sua autossuficiência energética. Contudo, o Brasil não pretendia abrir mão do gás boliviano no médio prazo. Em dezembro de 2009, Petrobras e YPFB assinaram um adendo ao gas supply agreement assegurando o fornecimento de 30 mil metros cúbicos diários de gás natural até 2019, nas condições adotadas a partir de 2006 (YPFB, 2009).

\section{Tabela 7 - Oferta de gás natural do Brasil, em metros cúbicos médios diários}

\begin{tabular}{|c|c|c|}
\hline & Produção nacional líquida & Importação \\
\hline 2005 & 26.752 & 24.640 \\
\hline 2006 & 27.073 & 26.819 \\
\hline 2007 & 26.932 & 28.299 \\
\hline 2008 & 34.482 & 30.917 \\
\hline 2009 & 28.161 & 22.294 \\
\hline
\end{tabular}

Fonte: ANP (2008: 24-25) e ANP (2010: 17).

\section{Conclusão}

A análise do comércio entre Brasil e Bolívia mostra que havia um processo gradual e positivo de integração econômica entre os dois países. Não houve uma retração no comércio, o Brasil manteve seus investimentos no país vizinho, e um grupo de trabalho preparou os termos de adesão da Bolívia ao Mercosul.

Esta análise também mostra que a ausência de impactos sociais relevantes por conta da integração econômica levou a Bolívia a querer revisar os seus termos, o que foi feito nos marcos de uma crise internacional em 2006. Como a demanda por gás natural cresceu nos anos seguintes, é difícil estimar com precisão se os resultados positivos obtidos posteriormente seriam mantidos caso o cenário econômico fosse de recessão.

O que é possível afirmar é que a Bolívia foi bem-sucedida na revisão dos termos da integração econômica em 2006. Além de obter uma melhora nas condições de comércio, foram mantidos abertos os canais de interlocução política, que permitiram a assinatura de acordos de cooperação técnica entre os países e assegurou à Bolívia financiamento brasileiro para projetos de seu interesse, além de não prejudicar sua integração com o Mercosul. É possível afirmar também que a disposição do governo brasileiro em adotar uma postura de diálogo e insistir na parceria mesmo após a crise de 2006 contribuiu positivamente para este cenário. Sobre as bases da interlocução política existente e do comércio internacional em expansão, retomou-se logo após a crise o círculo virtuoso de integração econômica entre os dois países. 


\section{Bibliografia}

AGÊNCIA NACIONAL DO PETRÓLEO. Boletim Mensal do Gás Natural. Brasília, n. 14, fev. 2010. Anexos do Boletim Mensal do Gás Natural. Brasília, dez. 2008.

ALICEWEB. Disponível em: <http://www.aliceweb.desenvolvimento.gov.br> Acesso em: 3.5.2010.

BALASSA, B. Theory of economic integration. Homewood: Richard D. Irwin, 1961.

BARUFI, Clara Bonumi; SANTOS, Edmilson Moutinho; IDE, Cristiane Reis. Autossuficiência e desenvolvimento: o comércio de gás natural entre Brasil e Bolívia. Cadernos Prolam/USP, São Paulo, ano 5, v. 2, p. 183-208, 2006.

BNAMERICAS. Petrobras, YPFB to sign gas supply y contract: online. Disponível em: <http:// www.bnamericas.com/news/electricpower/> Acesso em: 19.5.2010.

BRASIL. Decreto n. 3.131, 5 de outubro de 1938. Promulga o tratado sobre saída e aproveitamento do petróleo boliviano, entre o Brasil e a Bolívia, firmado no Rio de Janeiro a 25 de fevereiro de 1938. Disponível em: <http://www.mre.gov.br> Acesso em: 19.5.2010.

. Decreto n. 82.320, 27 de setembro de 1978. Promulga o acordo entre a República Federativa do Brasil e a República da Bolívia sobre a Instalação e o Funcionamento, na Cidade do Rio de Janeiro, de um Escritório de "Yacimientos Petrolíferos Fiscales Bolivianos". Disponível em: < http:// www.mre.gov.br> Acesso em: 19.5.2010.

. Nota do ministro das Relações Exteriores, 17 de agosto de 1992. Acordo, por troca de Notas, entre o Governo da República Federativa do Brasil e o Governo da República da Bolívia sobre a Compra e Venda de Gás Natural Boliviano à República Federativa do Brasil. Disponível em <http:/ /www.mre.gov.br> Acesso em: 19.5.2010.

. Nota do ministro das Relações Exteriores, 10 de março de 1993. Acordo, por troca de Notas Reversais, sobre a venda de gás boliviano ao Brasil, a propósito do contratro definitivo entre Petrobras e YPFB. Disponível em: < http://www.mre.gov.br> Acesso em: 19.5.2010.

Decreto n. 2.142, 5 de fevereiro de 1997. Promulga o Acordo para Isenção de Impostos Relativos à Implementação do Projeto do Gasoduto Brasil-Bolívia, celebrado entre o Governo da República Federativa do Brasil e o Governo da República da Bolívia, em Brasília, em 5 de agosto de 1996. Disponível em: <http://www.mre.gov.br> Acesso em: 19.5.2010.

. Memorando, 30 de março de 1998. Memorando de Entendimento entre a República Federativa do Brasil e a República da Bolívia sobre o Desenvolvimento de Intercâmbios Elétricos e Futura Integração Elétrica. Disponível em: <http://www.mre.gov.br> Acesso em: 19.5.2010.

. Visita de Estado do Presidente a La Paz, 17 de dezembro de 2007. Declaração Conjunta: "Brasil-Bolívia: avançando em direção a uma parceria estratégica”. Disponível em: <http:// www.mre.gov.br> Acesso em: 19.5.2010.

. Memorando, 17 de dezembro de 2007. Memorando de Entendimento em matéria energética entre o Ministério de Minas e Energia da República Federativa do Brasil e o Ministério de Hidrocarbonetos e Energia da República da Bolívia. Disponível em: <http://www.mre.gov.br> Acesso em: 19.5.2010.

Visita de trabalho do presidente a Riberalta, 18 de julho de 2008. Declaração de Riberalta: a infraestrutura como eixo da integração bilateral. Disponível em: <http://www.mre.gov.br > Acesso em: 19.5.2010. 
- Memorando, 12 de março de 2009. Memorando de Entendimento para a constituição de mecanismo de coordenação e cooperação Brasil-Bolívia. Disponível em: < http:/ /www.mre.gov.br> Acesso em: 19.5.2010.

CEPAL. Ensayos sobre coordinación de políticas macroeconómicas. Santiago de Chile: Cepal, 1992.

DEVLIN, Robert; FFRENCH-DAVIS, Ricardo. Towards and evolution of regional integration in Latin America in the 1990. Buenos Aires: INTAL, 1998.

FUNDO MONETÁRIO INTERNACIONAL. IMF Data Mapper. Disponível em: <http:// www.imf.org> Acesso em: 18.5.2010.

GIL, Aldo Durán. Bolívia e Equador no contexto atual. In: AYERBE, L. F. Novas lideranças políticase alternativas de governo na América do Sul. São Paulo: Unesp, 2008, p. 83-1 16.

INSTITUTO NACIONAL DE ESTADÍSTICAS. Comércio Exterior. Disponível em: <http://www. ine.gov.bo> Acesso em: 19.5.2010.

. Cuentas Nacionales. Disponível em: <http://www.ine.gov.bo> Acesso em: 19.5.2010.

. Encuesta trimestral de empleo. Disponível em: <http://www.ine.gov.bo> Acesso em: 19.5.2010.

INTAL. Integración energetica en el Cono Sur. Buenos Aires: INTAL, 1996.

KEYNES, John Maynard. A teoria geral do emprego, do juro e da moeda. São Paulo: Atlas, 1992.

MAISONNAVE, Fabiano. Revolta derruba o presidente boliviano. Folha de S. Paulo, 18 de outubro de 2003. Disponível em: <http://www.folha.uol.com.br/fsp> Acesso em: 19.5.2010.

. Votação dá fôlego a presidente boliviano. Folha de S. Paulo, 20 de julho de 2004. Disponível em: <http://www.folha.uol.com.br/fsp> Acesso em: 10.5.2010.

. Congresso boliviano rejeita renúncia de Mesa. Folha de S. Paulo, 9 de março de 2005. Disponível em: <http://www.folha.uol.com.br/fsp> Acesso em: 10.5.2010.

. Desfecho político reduz tensão na Bolívia. Folha de S. Paulo, 11 de junho de 2005. Disponível em: <http://www.folha.uol.com.br/fsp> Acesso em: 10.5.2010.

. Após vitória histórica, Morales critica EUA. Folha de S. Paulo, 20 de dezembro de 2005. Disponível em <http://www.folha.uol.com.br/fsp> Acesso em: 10.5.2010.

. Morales invade Petrobras e nacionaliza gás. Folha de S. Paulo, 2 de maio de 2006. Disponível em: <http://www.folha.uol.com.br/fsp> Acesso em: 10.5.2010.

MERCOSUl. Decisão n. 14/96, de 17 de dezembro de 1996. Participação de Terceiros Países Associados em Reunião do Mercosul. Disponível em: <http://www.mercosul.gov.br> Acesso em: 10.5.2010.

Decisão n. 38/03, de 15 de dezembro de 2003. Participação da Bolívia em Reuniões do Mercosul. Disponível em: <http://www.mercosul.gov.br> Acesso em: 10.5.2010.

. Decisão n. 1/07, de 18 de janeiro de 2007. Grupo de Trabalho ad hoc para a incorporação da República da Bolívia como estado parte do Mercosul. Disponível em: <http://www.mercosul.gov.br > Acesso em: 10.5.2010.

UCHOA, Rodrigo. Líder cocaleiro desestabiliza a Bolívia. Folha de S. Paulo, 14 de julho de 2002. Disponível em: <http://www.folha.uol.com.br/fsp> Acesso em: 10.5.2010.

YPFB. Hitos históricos. Disponível em: <http://www.ypfb.gov.bo> Acesso em: 10.5.2010. 